\title{
Tree-ring based reconstruction of mean maximum temperatures since AD 1829
}

\author{
by Zhongjie Shi ${ }^{1}$, Jixi Gao ${ }^{2,3}$, Xiaohui Yang1 ${ }^{1,3}$, Zhiqing Jia' ${ }^{1}$, Hao Guo ${ }^{1}$, Aiyun Song ${ }^{4}$, \\ Jianxun Shang ${ }^{5}$, Nan Shan ${ }^{1}$, Yun Tian ${ }^{1}$, Chaoyang Feng ${ }^{6}$ and Shihai Lü ${ }^{6}$
}

\begin{abstract}
The correlation between tree-ring widths and climate was developed using Pinus sylvestris var. mongolica after which mean maximum temperatures of June-July since 1829 were reconstructed. Results show that the transfer function of temperature explains more than $40 \%$ of the variance and that the reconstruction sequence was consistent with several reconstructed temperature variations in the region. Over the past 181 years, climate in the region has undergone eight distinct low temperature and eight high temperature periods. A high temperature period in the 1920s to 1930 s is consistent with a drought that occurred in most regions of northern China. Periods of drought in the 1870s were also identified. There was no significant increase or decrease in mean maximum June-July temperatures over the last 181 years, although since the 1950s temperatures have increased gradually. A warming trend has become more pronounced since the early 1990s but temperature levels are not significantly higher than those of the 1850s. A multi-taper spectral analysis shows that there are significant periodicities of 2.4, 2.8, 4.9, 5.1 and 21.3 years in the sequence of reconstructed temperatures. Temperatures were also affected by global climate events and solar activity.
\end{abstract}

Keywords: dendrochronology, temperature reconstructions, eco-climatology

\section{RÉSUMÉ}

Nous avons établi la corrélation entre la largeur des anneaux de croissance des arbres et le climat pour le Pinus sylvestris var. Mongolica, ce qui a permis de reconstituer les températures maximales moyennes des mois de juin et de juillet depuis 1829. Les résultats indiquent que la fonction de transfert de la température explique plus de $40 \%$ de la variance et que la reconstruction de la séquence était cohérente avec les variations d'autres reconstructions de la température effectuées dans la région. Au cours des 181 dernières années, le climat de la région a connu huit périodes distinctes de température froide et huit périodes de température élevée. La température élevée enregistrée entre 1920 et 1930 correspond à la sécheresse qui a affecté la plupart des régions du nord de la Chine. On a aussi pu mettre en évidence d’autres périodes de sécheresse survenues au cours des années 1870 . Il n’y a pas eu d’augmentation ou de diminution significative des températures maximales moyennes de juin et de juillet au cours des dernières 181 années, bien que les niveaux de température aient augmenté graduellement depuis les années 1950. La tendance au réchauffement sest accentuée depuis le début des années 1990, mais les niveaux de température ne sont pas sensiblement plus élevés que ceux des années 1850. Une analyse spectrale multitaper a révélé des périodicités de 2,4;2,8;4,9;5,1 et de 21,3 années dans la séquence des températures reconstituées. Les températures ont également été influencées par des phénomènes climatiques mondiaux et lactivité solaire.

Mots clés : dendrochronologie, reconstitution des températures, écoclimatologie

\section{Introduction}

Global climate change has a significant impact on natural ecosystems and socio-economic systems and has become a major issue of concern to governments and the scientific community worldwide. Studies of past climates are important because they enable an understanding of the background of recent climate changes and may allow for forecasting future climate changes (IPCC 2007). Due to the advantages of precise dating, tree-ring analysis plays an important role in studies to determine the mechanisms of past climate changes (Briffa et al. 1998, Mann et al. 1998, Cook et al. 2004).
China's tree-ring eco-climatology research, which studies relations between organisms and their climatic environment, did not begin until the 1980s (Wu et al. 1987). Most studies have focused on areas in the Tibetan Plateau (Zhang et al. 2003, Liang et al. 2008, Liu et al. 2009b, Liu et al. 2010) and other areas of northwestern China. A few studies of tree-ring eco-climatology have been carried out in the Changbai Mountains (Zhang et al. 2007, Zhu et al. 2009) and other regions in northeast China. However, eco-climatology research in northeast China remains limited. This is especially true for temperature reconstruction studies that have

\footnotetext{
${ }^{1}$ Institute of Desertification Studies, Chinese Academy of Forestry, Beijing 100091, China.

${ }^{2}$ Nanjing Institute of Environmental Sciences, Ministry of Environmental Protection, Nanjing 210042, China.

${ }^{3}$ Corresponding authors. E-mail: gjx@nies.org and yangxh@caf.ac.cn

${ }^{4}$ Research center for Eco-Environmental Sciences, Chinese Academy of Sciences, Beijing 100085, China.

${ }^{5}$ Songliao Water Resources Commission, Ministry of Water Resources, Changchun 130021, China.

${ }^{6}$ Research Institute of Ecology, Chinese Research Academy of Environmental Sciences, Beijing 100012, China.
} 
considered the past several hundred years. The Hulunbuir region is a transition zone from arid to semi-arid; it exhibits severe desertification and degradation and is sensitive to climate changes. This study used tree-ring data of Pinus sylvestris var. mongolica Litvin to analyze radial growth response to climate change. The objectives of the study were 1) to reconstruct the June-July maximum temperatures sequence since 1829,2 ) to provide high-resolution data to investigate historical climate change in the region, and 3) to provide an explanation for the response of vegetation to climate changes in arid and semi-arid regions of northeast China.

\section{Materials and Methods \\ Study area}

The Hulunbuir Xishan Forest Park and Huihe Reserve is a forest-steppe transition zone in Hulunbuir, Inner Mongolia. The region has a typical temperate monsoon climate-hot and rainy during the summer months and cold and dry in winter with an annual average temperature of $-2^{\circ} \mathrm{C}$. The average January temperature is $-25.8^{\circ} \mathrm{C}$ (minimum of $-48.5^{\circ} \mathrm{C}$ ), while the average July temperature is $19.9^{\circ} \mathrm{C}$ with a maximum of $36.7^{\circ} \mathrm{C}$. Average annual precipitation is approximately 350 $\mathrm{mm}, 68 \%$ of which falls June to August. Annual evaporation is some $1210 \mathrm{~mm}$, more than three times the annual rainfall. Pinus sylvestris var. mongolica is a hardy conifer growing on fixed sand dunes along the banks of the Yimin and Hui Rivers. The study area contains young sandy soil originating from quartz silt and is part of the Hailar River Basin of the Ergun River watershed (Fig. 1).

\section{Tree-ring data}

Fifty-four core samples from 26 trees were collected in Xishan Forest Park and 41 from 20 trees in Nanhui in the Hui River Nature Reserve (Fig. 1). Samples were pre-treated according to Stokes and Smiley (1968). After core samples were dried, glued and mounted, cross-dating was carried out using a skeleton diagram (Stokes and Smiley 1968) to ensure an accurate calendar year of each individual tree ring. Ring widths were measured with a Lintab5 ring analyzer enabling measurements to $0.001 \mathrm{~mm}$. Quality control of cross-dating used the COFECHA program (Holmes 1983) and samples with ambiguities were eliminated. After cross-dating, individual sequences of tree-ring widths were detrended and standardized using the ARSTAN program (Cook and Kairiukstis 1990). This eliminated undesirable growth trends involving age and non-coherent disturbance that occurred between some trees. In addition, this method excluded non-climate signals. To guarantee the maximum common signal at the lowest frequency possible and avoid impact caused by differences in growth rates among trees of different ages, each measurement sequence of tree-ring width was standardized by fitting a negative exponential function. All individual index sequences were combined into a single chronology by calculating the bi-weight robust mean. Standard chronology (STD), residual chronology (RES) and autoregressive chronology (ARS) were established for Xishan Forest Park and Nanhui separately (Table 1.). The analysis demonstrated that STD and RES of the two sample sites were quite close and suggests that climate information for the two sites is basically the same. Since changes in the chronology of the two sites were consistent and significantly correlated $(r=0.587, P<$ $0.001)$, they were combined to establish the regional standard chronology RS. The starting year of the chronology was determined by the subsample signal strength (SSS). The threshold of SSS in this study is defined as 0.85 . The effective period was from 1829 to 2009.

\section{Climatic data}

To determine the relationship between radial growth of Pinus sylvestris var. mongolica and climate and to address the lack of a regional climate signal caused by the meteorological station reflecting only the local climate signal, this study utilized monthly temperatures and monthly total precipitation collected at eight meteorological stations (Table 2). The climate is typical of East Asia in that a warm season coincides with a rainy season (Fig. 2). The variation in mean monthly temperatures and precipitation recorded by the meteorological sta-

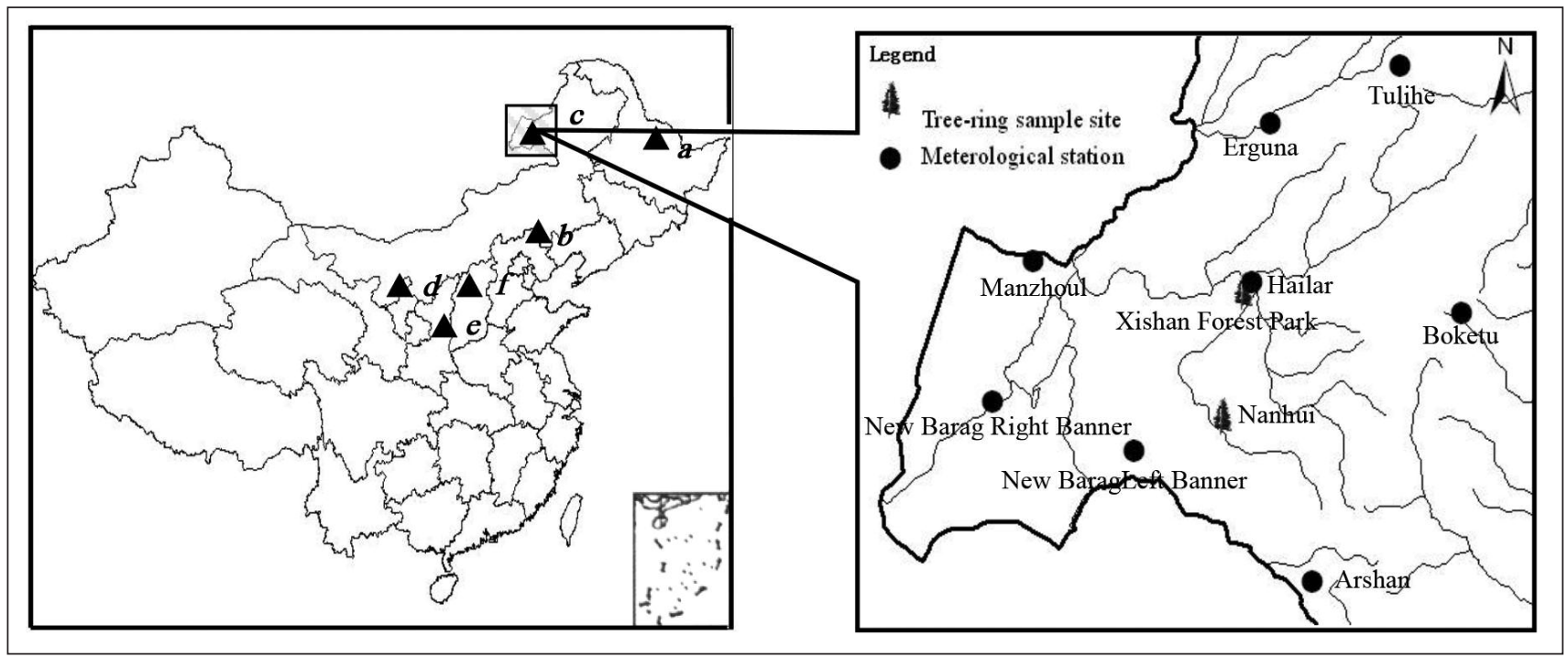

Fig. 1. Location of sample site (c), meteorological stations and sites of other studies (a, b, d, e, f). 
Table 1. STD of tree-ring width of Pinus sylvestris var. mongolica

\begin{tabular}{lccc}
\hline Basic statistics & XS & NH & RS \\
\hline Height above sea level (m) & $515-669$ & $692-751$ & - \\
Longitude & $119^{\circ} 42^{\prime}$ & $119^{\circ} 16^{\prime}$ & - \\
Latitude & $49^{\circ} 12^{\prime}$ & $48^{\circ} 17^{\prime}$ & - \\
Samples/trees & $44 / 26$ & $41 / 20$ & $85 / 46$ \\
Mean correlation between trees & 0.520 & 0.418 & 0.469 \\
Autocorrelation order 1 & 0.408 & 0.336 & 0.372 \\
Mean sensitivity & 0.264 & 0.199 & 0.231 \\
Mean tree-ring width & 0.985 & 0.982 & 0.983 \\
Standard deviation & 0.275 & 0.213 & 0.244 \\
Signal to noise ratio & 35.808 & 27.310 & 31.559 \\
Expressing population signal & 0.973 & 0.965 & 0.969 \\
Variance in first eigenvector & $54.44 \%$ & $45.45 \%$ & $49.95 \%$ \\
Chronology common interval & 0.982 & 0.990 & 0.986 \\
$\quad$ mean & & & \\
Starting year/Number of core & $1829 / 6$ & $1899 / 8$ & $1829 / 6$ \\
$\quad$ samples with SSS > 0.85 & & & \\
\hline
\end{tabular}

tions was similar. Maximum precipitation was recorded in July at all stations. Precipitation varied at the regional scale, decreasing from east to west.

Large-scale climate variables such as the Pacific Decadal Oscillation index (PDO; http://www/cdc.noaa.gov/Climate Indices/List), the North Atlantic Oscillation (NAO; http:// www.cru.uea.ac.uk/cru/data/nao/), solar radio flux and the sunspots numbers were used to assess the tree ring based climatic signals.

\section{Results and Discussion \\ Tree-ring climatic response}

Tree-ring width index was positively correlated with monthly total precipitation from eight meteorological stations with a significant correlation June to August of the current year. There was no significant correlation between tree-ring widths and precipitation from the previous October to April of the current year (Fig. 3). With the exception of the Hailar Station, tree-ring width index was positive but not significantly related to mean temperatures and mean maximum temperatures of the current May and previous October to December period. Tree-ring widths were negatively related to monthly mean temperatures and maximum temperatures from Janu-

Table 2. Data from meteorological stations

\begin{tabular}{lcccc}
\hline $\begin{array}{l}\text { Meteorological } \\
\text { station }\end{array}$ & Longitude & Latitude & $\begin{array}{c}\text { Height above } \\
\text { sea level/m }\end{array}$ & $\begin{array}{c}\text { Time } \\
\text { interval }\end{array}$ \\
\hline Hailar & $119^{\circ} 45^{\prime}$ & $49^{\circ} 13^{\prime}$ & 610.2 & $1951.10-2008.12$ \\
Erguna & $120^{\circ} 11^{\prime}$ & $50^{\circ} 15^{\prime}$ & 581.4 & $1957.10-2008.12$ \\
Boketu & $121^{\circ} 55^{\prime}$ & $48^{\circ} 46^{\prime}$ & 739.7 & $1951.10-2008.12$ \\
Manzhouli & $117^{\circ} 26^{\prime}$ & $49^{\circ} 34^{\prime}$ & 661.7 & $1956.12-2008.12$ \\
New Barag Left Banner & $118^{\circ} 16^{\prime}$ & $48^{\circ} 13^{\prime}$ & 642.0 & $1958.11-2008.12$ \\
New Barag Right Banner & $116^{\circ} 49^{\prime}$ & $48^{\circ} 40^{\prime}$ & 554.2 & $1957.10-2008.10$ \\
Tulihe & $121^{\circ} 41^{\prime}$ & $50^{\circ} 29^{\prime}$ & 732.6 & $1957.10-2008.12$ \\
Arshan & $119^{\circ} 56^{\prime}$ & $47^{\circ} 10^{\prime}$ & 997.2 & $1952.60-2008.12$ \\
\hline
\end{tabular}

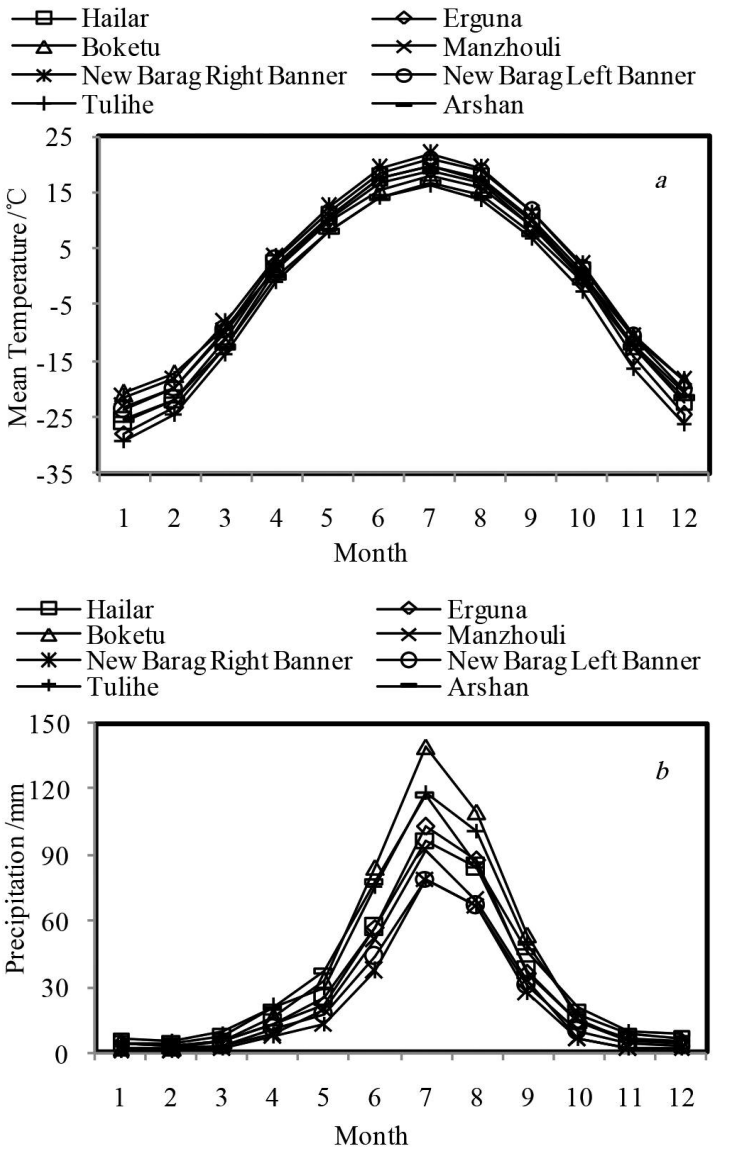

Fig. 2. Changes in mean monthly temperatures (a) and precipitation (b) at meteorological stations.

ary to April and June to October of the current year at all stations, with a significant negative correlation with the mean maximum temperature of April and from June to July at most stations (Fig. 3). The positive relationship between chronology and monthly precipitation and the negative relationship between chronology and mean temperatures reflects the response pattern of radial growth to climate change in arid and semi-arid areas and indicates that increasing precipitation will lead to wider tree rings while higher temperatures may lead to narrower rings. Comparison of the correlation coefficients of tree-ring width index and monthly mean temperatures and monthly mean maximum temperatures June to October shows that the correlation coefficient of mean maximum temperatures was much higher than mean temperatures, especially for June and July.

There is a definite physiological significance for the negative correlation between June-July mean maximum temperatures and tree-ring widths, and the positive correlation between tree-ring widths and precipitation. Pinus sylvestris var. mongolica grows rapidly from June to August. It is able to tolerate cold, dry conditions but its 
endurance at high temperatures is poor (Pichler and Oberhuber 2007).

Precipitation increases soil moisture but temperature, especially maximum temperatures, reduces soil moisture by increasing plant transpiration and soil water evaporation. Pinus sylvestris var. mongolica mainly occurs north of Daxinganling, which has an annual precipitation of $400 \mathrm{~mm}$ to $600 \mathrm{~mm}$. However, the average annual precipitation of $360 \mathrm{~mm}$ recorded at the meteorological stations is insufficient for maximum growth potential of trees in this study. The significant negative correlation of radial growth with mean temperatures and mean maximum temperatures during the growing season shows that higher temperatures indirectly limit the growth of trees via soil water evaporation and plant transpiration (Liang et al. 2001). Soil water is primarily used by trees in this study from June to August, especially in July when temperatures are highest (Bai et al. 2011). The highest precipitation is in July-August but mean temperatures are highest in June-July (Fig. 2). At this time a soil water deficit occurs because of increased water demand due to transpiration. Soil water evaporation is greater than precipitation and accordingly, moisture requirements for growth cannot be met. As a result, temperatures, especially average maximum temperatures, become key factors that limit the radial growth of trees. Increasing mean temperatures and mean maximum temperatures in the growing season will reduce tree-ring widths, while lower temperatures will increase the width of tree rings. Results also show that the effect of mean maximum temperatures from June-July was greater than the effect of precipitation during the same period. These findings are similar to studies on the Qinghai-Tibet Plateau (Shi et al. 2010).

Variations in temperatures over the year were consistent among meteorological stations (Fig. 2). Therefore, the relationship of ring width and June-July mean maximum temperatures from 1957 to 2009 was examined. Results show that June-July mean maximum temperatures represented by treering widths can represent a wide range of temperature conditions in the Hulunbuir area.

\section{Mean maximum temperature reconstruction}

The transfer function is established by linear regression using the STD chronology of

Pinus sylvestris var. mongolica and average June-July mean maximum temperatures determined from the eight meteorological stations from 1957 to 2009. The transfer function is as follows:

$$
\text { [1] } \mathrm{T}_{\mathrm{i}}=-4.8086 \mathrm{~W}_{\mathrm{i}}+29.2134
$$
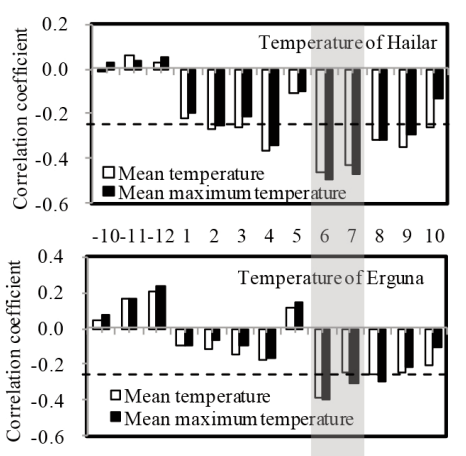

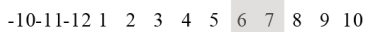

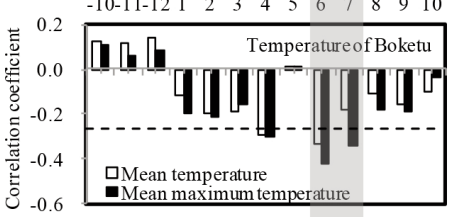

$\begin{array}{lllllllllll}-10-11-12 & 1 & 2 & 3 & 4 & 5 & 6 & 7 & 8 & 9 & 10\end{array}$

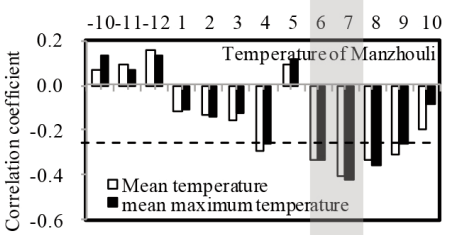

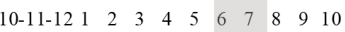

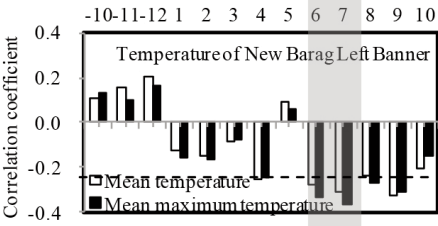

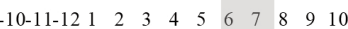

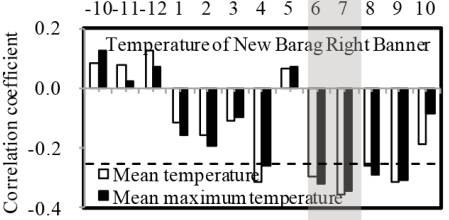

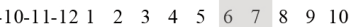

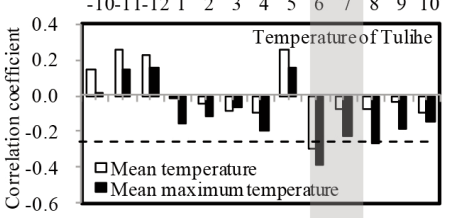

-10-11-12 $120 \begin{array}{lllllllll} & 3 & 4 & 5 & 6 & 7 & 8 & 9 & 10\end{array}$
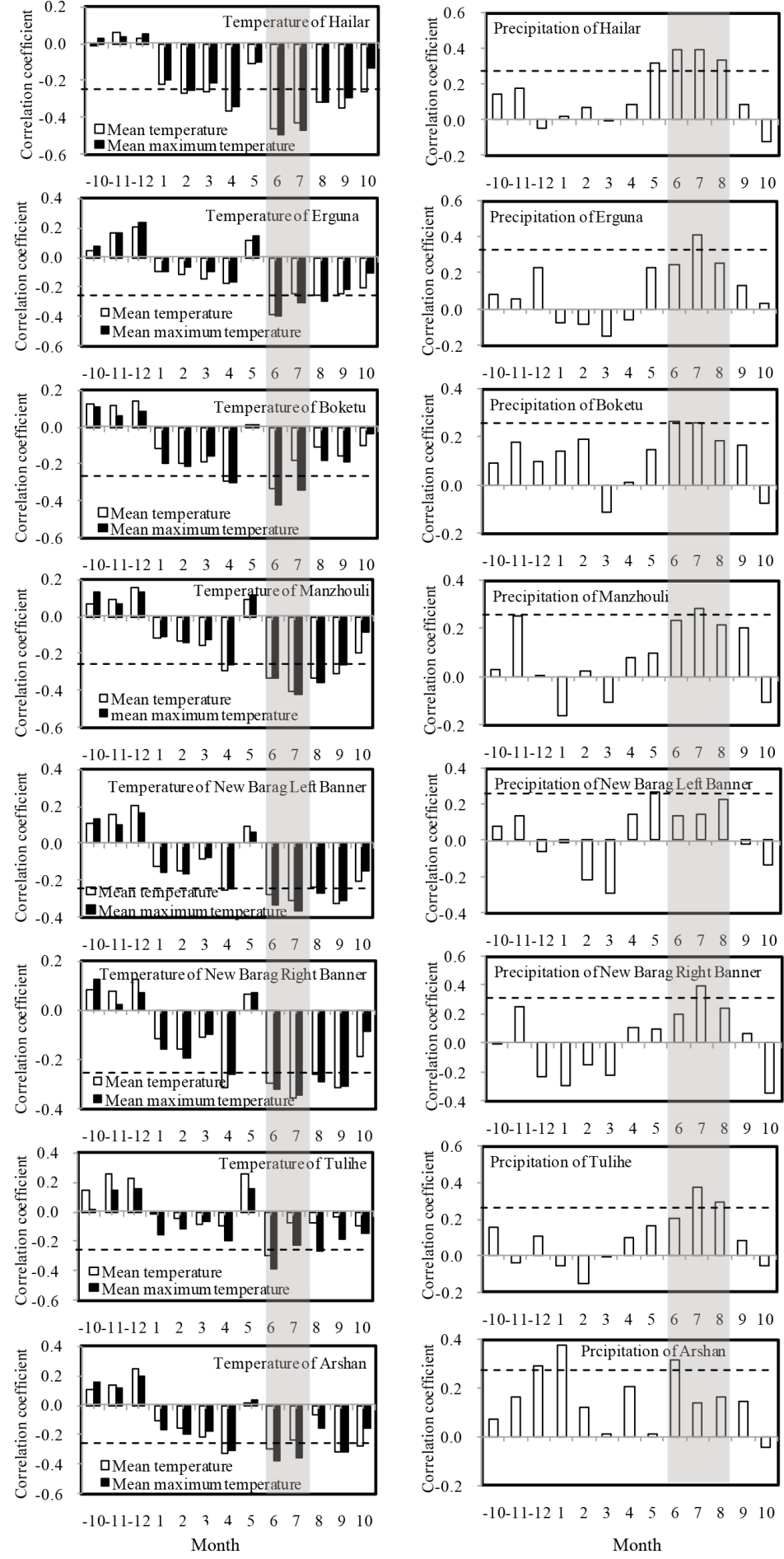

$\begin{array}{lllllllllll}-10-11-12 & 1 & 2 & 3 & 4 & 5 & 6 & 7 & 8 & 9 & 10\end{array}$

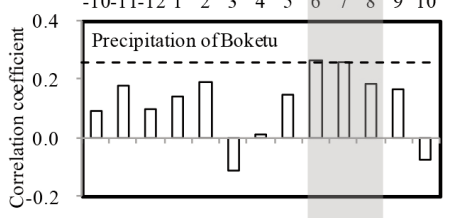

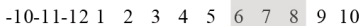

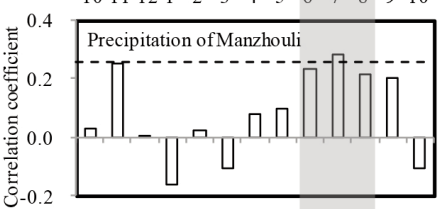

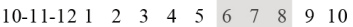
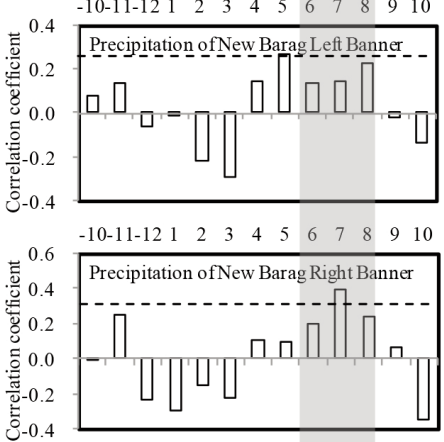

$\begin{array}{lllllllllll}-10-11-12 & 1 & 2 & 3 & 4 & 5 & 6 & 7 & 8 & 9 & 10\end{array}$
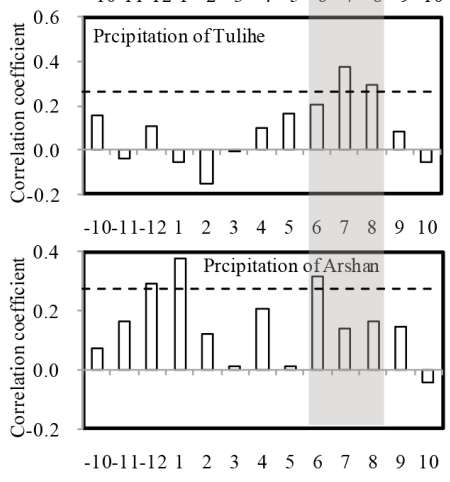

Month

Fig. 3. Correlation between ring width, temperature and precipitation at eight meteorological stations. The dotted line is $95 \%$ confidence.

where $\mathrm{T}_{\mathrm{i}}$ is the June-July mean maximum temperature $\left({ }^{\circ} \mathrm{C}\right)$ in year $\mathrm{i} ; \mathrm{W}_{\mathrm{i}}$ the STD tree-ring width index in year $\mathrm{i}$. The correlation coefficient of eq. 1 is $0.64(P<0.00001, n=53)$, with an explained variance of $40.39 \%$ (39.33\% after adjustment for loss of degrees of freedom) during the calibration period of 1957 to 2009 . The value of the $F$ test is 37.95 . 


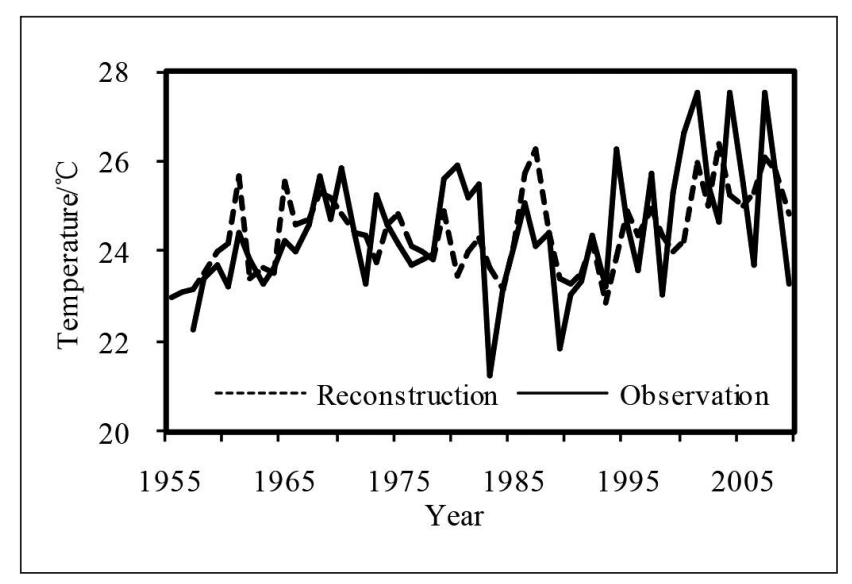

Fig. 4. Comparison of reconstructed and observed June-July mean maximum temperatures.

level. These findings suggest that reconstruction of low-frequency variation by the transfer function is better than by the high-frequency variation. The other test values, including reduced error $(\mathrm{RE}=0.618)$, product mean $(t=7.114)$, correlation coefficient $(r=0.60)$ and $F$ value of the equation $(F=$ 37.95), were also significant at $P=0.01$, which indicates that the transfer function is stable and reliable.

June-July mean maximum temperatures of the Hulunbuir area from 1829 to 2009 were reconstructed according to the transfer function of eq. 1 (Fig. 5). Reconstruction indicated that the mean maximum temperature over the past 181 years was $24.5^{\circ} \mathrm{C}$, with a standard deviation $(\sigma)$ of $\pm 1.03^{\circ} \mathrm{C}$. Years with a mean maximum temperature $>$ mean value $+\sigma$ are considered extreme high-temperature years; those with a mean maximum temperature $<$ mean value $-\sigma$ as extreme low-temperature years. During the last 181 years, there were 33 extreme high-temperature years in the Hulunbuir Area, accounting for $18.3 \%$ of the study period. These included three extreme high-temperature events lasting more than three years in the reconstructed sequence: 1905-1909 (mean maximum temperature $\left.26.3^{\circ} \mathrm{C}\right), 1926-1928\left(26.3^{\circ} \mathrm{C}\right)$, and $1935-1937\left(25.9^{\circ} \mathrm{C}\right)$. There were also 29 extreme low-temperature years accounting for $16.0 \%$ of the total years. Moreover, three extreme lowtemperature events lasting for three years were found: $1845-1848$ $\left(22.9^{\circ} \mathrm{C}\right), 1866-1870\left(22.9^{\circ} \mathrm{C}\right)$ and 1953-1957 $\left(23.2^{\circ} \mathrm{C}\right)$. The periods 1926-1928 and 1935-1937 were characterized by severe drought that led to tremendous loss of life in northern China, recognized by other studies (Liu et al. 2005, Liang et al. 2006, Cai et al. 2008). The June-July mean max-

Fig. 5. Reconstructed June-July mean maximum temperatures in Hulunbuir (1829-2009) The smoothing line is the 11-year moving average.

Comparison of actual and estimated maximum temperatures during the observation period (Fig. 4) reveals that change trends are homologous and estimated values agree well with actual values. These findings demonstrate that the reconstruction function is credible. However, due to the relatively short meteorological dataset (1957 to 2009), it is not possible to evaluate the quality and stability of eq. 1 using the split-sampling calibration and verification method. Accordingly, the stability and accuracy of the June-July mean maximum temperature transfer function was tested by cross-validation (Mosteller and Tukey 1977). Results show (Table 3) that the sign test of the raw data found 37 instances of agreement at the 0.01 significance level, but the sign test of the firstorder difference was 32 , which is not significant at the 0.05 imum temperature reached the highest value in 1853 , while the year with lowest mean maximum temperature in the past 181 years was 1868 .

On the decadal timescale, the reconstructed sequence reveals June-July mean maximum temperature variability. When an 11-year moving average was used for the reconstructed sequence, the mean maximum temperature smoothing curve showed distinct alternations of cold and warm periods. Overall, there were eight cold periods and eight warm periods (Table 4). The longest cold period lasted for 27 years (1937 to 1963), while the longest warm period was 17 years (1920 to 1936). Based on the general changes and trends in the 11-year moving average of the reconstructed sequence over the past 181 years, June-July mean maximum temperatures showed no significant trend toward cooler or warmer.

Table 3. Statistics of transfer function and cross validation

\begin{tabular}{|c|c|c|c|c|c|c|c|c|c|}
\hline $\begin{array}{l}\text { Time } \\
\text { interval }\end{array}$ & $\begin{array}{l}\text { Explained } \\
\text { variance }\end{array}$ & $\begin{array}{l}\text { Adjusted } \\
\text { value of } \\
\text { explained } \\
\text { variance }\end{array}$ & $F$ value & $\begin{array}{l}\text { Sign test } \\
\text { S1 }\end{array}$ & $\begin{array}{c}\text { Sign test } \\
\text { of first-order } \\
\text { difference } \\
\text { S2 }\end{array}$ & $\begin{array}{c}\text { Product } \\
\text { mean } \\
t\end{array}$ & $\begin{array}{l}\text { Reduced } \\
\text { error }\end{array}$ & $\begin{array}{c}\text { Related } \\
\text { coefficient } \\
r\end{array}$ & $P$ \\
\hline 1957-2009 & $40.39 \%$ & $39.33 \%$ & 37.949 & $37+/ 15^{*}$ & $32+/ 19-$ & 7.114 & 0.618 & 0.60 & $<0.00001$ \\
\hline
\end{tabular}

Note: ${ }^{*}$ The confidence level of $99 \%$ has been reached. 
Table 4. High/low temperature periods and their anomalies based on June-July maximum temperature from 1829 to 2009

\begin{tabular}{cccccc}
\hline $\begin{array}{c}\text { Time } \\
\text { High temperature period }\end{array}$ & & \multicolumn{2}{c}{ Low temperature period } \\
\cline { 1 - 2 } \cline { 5 - 6 } interval & $\begin{array}{c}\text { Anomaly } \\
\text { value }\left({ }^{\circ} \mathbf{C}\right)\end{array}$ & & $\begin{array}{c}\text { Time } \\
\text { interval }\end{array}$ & $\begin{array}{c}\text { Anomaly } \\
\text { value }\left({ }^{\circ} \mathbf{C}\right)\end{array}$ \\
\hline $1837-1839$ & 0.07 & & $1834-1836$ & -0.12 \\
$1851-1862$ & 0.62 & & $1840-1850$ & -0.42 \\
$1875-1882$ & 0.16 & & $1863-1874$ & -0.46 \\
$1890-1894$ & 0.10 & & $1883-1889$ & -0.02 \\
$1900-1912$ & 0.46 & & $1895-1899$ & -0.06 \\
$1920-1936$ & 0.51 & & $1913-1919$ & -0.07 \\
$1964-1972$ & 0.11 & & $1937-1963$ & -0.38 \\
$1998-2004$ & 0.52 & & $1973-1997$ & -0.28 \\
\hline
\end{tabular}

The June-July mean maximum temperature from the 1850 s to the early 1860 s was the highest during the 181 years. From the 1880 s to the early $20^{\text {th }}$ century, temperature changes were small and the mean maximum temperature dropped after the 1930s. Since the end of the 1950s June-July mean maximum temperatures have increased slowly, especially since the 1990s.

To verify the reconstruction, it was compared with five other tree-ring-based temperature reconstructions conducted in the region (Fig. 6). The reconstruction in this study illustrated similar high/low temperature intervals to these other studies. Over the past 181 years, high-temperature periods in the early 20th century and the 1920 s to 1930 s, the low-temperature period in the 1950s and the gradual warming trend since 1950 were consistent among the studies. With the exception of the temperature sequence of Mt. Helan, all other temperature sequences captured the warming trend that has occurred since the 1990s (Fig. 6). The warm 1850s to 1860 s occurred in three of the temperature sequences. However, the mean maximum temperature variations reconstructed in this study were relatively stable from 1875 to 1900 , while in Huanglong, Shanxi Province (Cai et al. 2008), Mt. Beiwudang (Cai et al. 2010) and Mt. Helan (Cai and Liu 2006) indicate it was a low temperature period, and a high temperature period in Wuying, Heilongjiang Province (Yin et al. 2009).

According to meteorological data for the study area from 1957 to 2009, June-July mean maximum temperatures in the Hulunbuir area were significantly negatively correlated with precipitation during the same period $(r=-0.64, P<0.001)$, indicating that there was little precipitation during the high-temperature season. Summer in northern China is always associated with drought, while low temperatures are associated with floods. The severe drought in North China from 1876 to 1879 was captured in the data from the Hulunbuir area. According to historical records, a continuous drought occurred in Qiqihar and Moergen (now Nenjiang County) near Hulunbuir in the spring and summer of 1875 . The local government exempted the food tax in those disaster areas until 1879 (Shen 2008). The reconstructed June-July mean maximum temperature sequence shows that temperatures began to rise in 1875 and peaked in 1878. The reconstruction sequence also shows that an extreme high temperature event occurred during 1905-1909 when the mean maximum temperature was $1.75^{\circ} \mathrm{C}$ higher than the average value of the past 181 years. According to the Inner Mongolia Volume of China Meteorological Disaster Dictionary (Shen 2008), there was no rainfall from spring to autumn in 1909 , and only $30 \%$ to $40 \%$ of the crops were harvested compared to normal harvest years. From the late 1920s to the middle of the 1930s, an extreme drought caused serious social and economic problems in northern China and the death toll reached 1.2 billion, accounting for $30 \%$ of China's population at the time (Ding 2008). According to Shen (2008), a drought in 1926 was the result of April to July rains being 50\% below
Fig. 6. Comparison of reconstructed temperature sequences. Curves (a)-(e) were obtained by 11-year moving average of sequences. (a) October mean temperature of Wuying, Heilongiang (Yin et al. 2009); (b) May-June mean temperatures of Weichang, Hebei Province (Liu et al. 2009a); (c)June-July mean maximum temperatures of Hulunbuir reconstructed in this study; (d) January-August mean temperatures of Mt. Helan (Cai and Liu 2006); (e) April-September mean temperatures of Huanglong, Shaanxi Province (Cai et al.2008); (f) May-July mean temperatures of Mount Beiwudang, Shanxi Province (Cai et al.2010). 
average in the Hailar and Zhalantun areas. A drought in the summer of 1927 prevented crops from reaching harvest size in 1928, and no rains in the spring and summer of 1929 caused all grain crops to die. In 1935 most of areas in the Hulunbuir region were subject to a continuous drought in spring and summer, and this drought was especially severe in Hailar (Ding 2008). According to the reconstruction sequence in this study, the June-July mean maximum temperatures from 1925 to 1931 was $1.28^{\circ} \mathrm{C}$ higher than the average of the past 181 years and $1.80^{\circ} \mathrm{C}$ higher than the average in 1926 to 1928. Furthermore, from 1935 to 1937, temperatures were $1.34^{\circ} \mathrm{C}$ higher than the average of the past 181 years. The continuous temperature-rise event observed in this study occurs at the same time as the disastrous drought from the 1920s to the 1930s, which is also observed in the results of tree-ring temperature reconstruction conducted in many regions in northern China (Liang et al. 2007, Cai et al. 2008).

\section{Linkages with remote oceans and solar activity}

Significant peaks were found at 2.4, 2.8, 4.9, 5.1 and 21.3 years $(P<0.05)$ by the multi-taper method of spectral analysis. The two- to five-year cycle falls within the range of variability of the El Niño-Southern Oscillation (Liu and Wang 2001, Huber and Caballero 2003, McPhaden et al. 2006), and the connection is supported by the correlation between the reconstruction and the January-February and March-May Southern Oscillation Index. A significant peak in temperature at 21.3 years may correspond to one found in a reconstructed Pacific Decadal Oscillation series (Biondi et al. 2001, D’Arrigo et al., 2001). Correlation between reconstructed temperatures and the Pacific Decadal Oscillation series shows a possible impact on temperature. Climate variability and local tree radial growth are also affected by the North Atlantic Oscillation (He et al. 2007, Li et al. 2009, Zhu et al. 2009, Chen et al. 2011). The significant correlation $(r=-0.287, P<0.05)$ between reconstructed temperatures and the summer North Atlantic Oscillation shows a possible impact by the Westerlies on temperatures in the study area.

In addition, peaks in temperature at 5.1 and 21.3 years are consistent with the oscillation cycle of solar activity. Correlation coefficients of the June-July mean maximum temperature sequence with September to May sunspot number sequence from 1829 to 2009 reached $-0.143(P<0.05)$. The reconstructed temperature sequence is also correlated with the solar radio flux $(r=-0.307, P<0.01)$. These findings indicate that solar activity plays an important role in variations of the mean maximum temperature in the study area.

\section{Conclusion}

Tree-ring widths of Pinus sylvestris var. mongolica in the Hulunbuir region in response to climate indicate that radial growth is positively correlated with monthly summer precipitation and negatively correlated with monthly mean temperatures and monthly mean maximum temperatures. Radial growth is sensitive to variations of regional temperature and precipitation. This is especially true for the June-July mean maximum temperatures, which had more influence than precipitation during the same period. The June-July mean maximum temperature variations were reconstructed using a transfer function, and the transfer function explains $40.4 \%$ of the variance (the adjusted explained variance is $39.3 \%, F=$ 37.95 and $P<0.00001, n=53)$. The temperature reconstruc- tion sequence in the Hulunbuir area is consistent with the tree-ring reconstructed temperature variations in other studies. In addition, the reconstructed temperatures have been verified based on the records of historical meteorological disasters, which show that the reconstruction sequence is reliable. The 11-year smoothing curve of June-July mean maximum temperatures showed some distinct low-high temperature alternations, with eight low-temperature periods and eight high-temperature periods over the past 181 years. Among these, the warm period in the 1920 s to 1930 s is consistent with a drought that was recorded in most regions in northern China. In addition, drought events in North China in the 1870 s were also reflected in data pertaining to the Hulunbuir area. There was no significant warming or cooling observed when the mean maximum temperature of June-July over the last 181 years was considered. The highest mean maximum temperature appeared in the period from the 1850 s to early 1860 s. From the 1880 s to the early $20^{\text {th }}$ century, the change in temperature was small and the mean maximum temperature decreased after the 1930s. At the end of the 1950s, June-July mean maximum temperatures started to increase slowly, and this warming trend became more pronounced after the 1990s. Multi-taper spectral analysis showed that June-July mean temperatures over the past 181 years had significant periodicities of $2.4,2.8,4.9,5.1$ and 21.3 years, which is consistent with the oscillation period of ENSO and solar activity. The temperature is affected by El Niño/Southern Oscillation, Pacific Decadal Oscillation and North Atlantic Oscillation. This relationship shows that climate changes in the Hulunbuir area are subject to the impact of local climate changes and may reflect a regional response to global climate changes.

\section{Acknowledgements}

This research was supported by grants from the Forestry Commonweal Research Special Program (201204203), Environmental Protection Commonweal Research Special Program $(200809125 ; 200909021)$, and the National Natural Science Foundation of China (41271033; 30700640; 40801017). We also thank Professor Xuemei Shao of the Institute of Geographic Sciences and Natural Resources Research of the Chinese Academy of Science for her help and meticulous guidance, as well as for providing the program used for power spectral analysis. In addition, we thank Dr. Hong Yin for providing the temperature reconstructed sequence of Wuying, Heilongjiang Province.

\section{References}

Bai, X.F., H. Han, F.Y. Zhou, R.S. Zhang, G.J. Zhao and J.H. Liu. 2011. Study on ecological characteristics of transpiration and water consumption of Pinus sylvestris var. mongolica in sand. J. Tech. Un. Natural Science 30(3): 404-407. [In Chinese with English abstract]. Biondi, F., A. Gershunov and D. Cayan. 2001. North Pacific decadal climate variability since AD 1661. J. of Climate 14: 5-10.

Briffa, K.R., F.H. Schweingruber, P.D. Jones, T.J. Osborn, S.G. Shiyatov and E.A. Vaganov. 1998. Reduced sensitivity of recent tree-growth to temperature at high northern latitudes. Nature 391: 678-682.

Cai, Q.F. and Y. Liu. 2006. Temperature variability since 1776 inferred from tree-rings of Pinus tabulaeformis in Mt. Helan. Acta Geographica Sinica 61(9): 929-936.

Cai, Q.F., Y. Liu, G. Bao, Y. Lei and B. Sun. 2010. Tree-ring-based May-July mean temperature history for Lüliang Mountains, China, 
since 1836. Chinese Science Bulletin 55. doi: 10.1007/s11434-0103235-Z.

Cai, Q.F., Y. Liu, H.M. Song and J.Y. Sun. 2008. Tree-ring-based reconstruction of the April to September mean temperature since 1826 AD for north-central Shaanxi Province, China. Sci. in China Series D: Earth Science 51(8): 1099-1106.

Chen, Z., X. He, E.R. Cook, H.S. He, W. Chen, Y. Sun and M. Cui. 2011. Detecting dryness and wetness signals from tree rings in Shenyang, Northeast China. Palaeogeo., Palaeoclimato., Palaeoecolo., 302: 301-310. doi:10.1016/j.palaeo.2011.01.018.

Cook, E.R. and L.A. Kairiukstis. 1990. Methods of Dendrochronology: Applications in Environmental Sciences. Kluwer Academic Publishers, Dordrecht, Netherlands.

Cook, E.R., Woodhouse, C.A., Eakin, C.M. 2004. Long-term aridity changes in the western United States. Sci. 306: 1015-1018.

D’Arrigo, R., G. Jacoby, D. Frank, N. Pederson, E. Cook, B. Buckley, B. Nachin, R. Mijiddorj and C. Dugarjav. 2001. 1738 years of Mongolian temperature variability inferred from a tree-ring width chronology of Siberian pine. Geophysical Res. Letters 28(3): doi: 10.29/2000GLO11845.

Ding, Y.H. 2008. Meteorological Disasters Dictionary of China: Vol. Comprehensive. Beijing: Meteorological Press. [In Chinese with English abstract].

He, X.Y., Z.J. Chen, W. Chen, X.M. Shao, H.S. He and Y. Sun. 2007. Solar activity, global surface air temperature anomaly and Pacific Decadal Oscillation recorded in urban tree rings. Ann. For. Sci. 64: 743-756.

Holmes, R.L. 1983. Computer-assisted quality control in tree-ring dating and measurement. Tree-Ring Bull. 43: 69-78.

Huber, M. and R. Caballero. 2003. Eocene El Nino: Evidence for robust tropical dynamics in the "Hothouse". Sci. 299: 877-881.

[IPCC] Intergovernmental Panel on Climate Change. 2007. Climate Change 2007: Impacts, Adaptation \& Vulnerability. Cambridge University Press, Cambridge, UK.

Li, J., E.R. Cook, R. D'arrigo, F. Chen and X. Gou. 2009. Moisture variability across China and Mongolia:1951-2005. Clim. Dyn. 32: 1173-1186. doi:10.1007/s00382-008-0436-0.

Liang, E.Y., X.H. Liu, Y.J. Yuan, N.S. Qin, X.Q. Fang, L. Huang, H.F. Zhu, L.L. Wang and X.M. Shao. 2006. The 1920s drought recorded by tree rings and historical documents in the semi-arid and arid areas of northern China. Clim. Change 79: 403-432.

Liang, E.Y., X.M. Shao, Y.X. Hu and J.X. Lin. 2001. Dendroclimatic evaluation of climate-growth relationships of Meyer spruce (Picea meyeri) on a sandy substrate in semi-arid Grassland, North China. Trees-Structure Function 15(4): 230-235.

Liang, E.Y., X.M. Shao, H.Y. Liu and D. Eckstein. 2007. Tree-ring based PDSI reconstruction since AD 1842 in the Ortindag sand land, east Inner Mongolia. Chin. Sci. Bull. 52(19): 2715-2721.

Liang, E.Y., X.M. Shao and N.S. Qin. 2008. Tree-ring based summer temperature reconstruction for the source region of the Yangtze River on the Tibetan Plateau. Global and Planetary Change 61: 313-320.

Liu, J.J., B. Yang and C. Qin. 2010. Tree-ring based annual precipitation reconstruction since AD 1480 in south central Tibet. Quaternary Int.. doi:10.1016/j.quaint.2010.03.020.
Liu, S. and N. Wang. 2001. The impacts of antecedent ENSO event on air temperature over northeast China in summer. J. Trop. Meteorol. 17(3): 314-319.

Liu, Y., Q.F. Cai, J.F. Shi, M.K. Hughes, J.E. Kutzbach, Z.Y. Liu, F.B. Ni and Z.S. An. 2005. Seasonal precipitation in the south-central Helan Mountain region, China, reconstructed from tree-ring width for the past 224 years. Can. J. For. Res. 35(10): 2403-2412.

Liu, Y., H. Tian, H.M. Song, J.M. Liang, Q.F. Cai and J.Y. Sun. 2009a. Tree ring based reconstruction of the May-June mean temperature since A.D. 1884 in Weichang, Hebei Province, China. Quaternary Science 29(5): 896-904.

Liu, Y., Z.S. An, H.W. Linderholm, D.L. Chen, H.M. Song, Q.F. Cai, J.Y. Sun and H. Tian. 2009b. Annual temperatures during the last 2485 years in the mid-eastern Tibetan Plateau inferred from tree rings. Science in China Series D-Earth Science 52: 348-359.

Mann, M.E., R.S. Bradley and M.K. Hughes. 1998. Global-scale temperature patterns and climate forcing over the past six centuries. Nature 392: 779-787.

McPhaden, M.J., S.E. Zebiak and M.H. Glantz. 2006. ENSO as an integrating concept in Earth Science. Sci. 314: 1740-1745.

Mosteller, F. and J.W. Tukey. 1977. Data Analysis and Regression. Addison-Wesley Publishing Company, Reading, MA.

Pichler, P. and W. Oberhuber. 2007. Radial growth response of coniferous forest trees in an inner Alpine environment to heat-wave in 2003. For. and Ecol. Manag. 242: 688-699.

Shen, J.G. 2008. Meteorological Disasters Dictionary of China: Vol. Inner Mongolia. Meteorological Press, Beijing. [in Chinese].

Shi, X.H., N.S. Qin, H.F. Zhu, X.M. Shao, Q.C. Wang and X.D. Zhu. 2010. May-June mean maximum temperature change during 1360-2005 as reconstructed by tree ring of Sabina Tibetica in Zaduo, Qinghai Province. Chinese Science Bulletin 55. doi: 10.1007/s11434010-3237-x

Stokes, M.A. and T.L. Smiley. 1968. An Introduction to Tree-Ring Dating. University of Chicago Press, Chicago, IL.

Wu, X.D., Z. Cheng and L. Sun. 1987. Status of dendrochronological work in China. Dendrochronologia 5: 127-133.

Yin, H., P.W. Guo, H.B. Liu, L. Huang, H.M. Yu, S.Y. Guo and F. Wang. 2009. Reconstruction of the October mean temperature since 1796 from tree ring data at Wuying of Xiaoxinganling Mountains. Advance in Climate change Research 5(1): 18-23.

Zhang, H.S., S.J. Han, Y.W. Li and J.H. Zhang. 2007. Reconstruction of temporal variations of precipitation in Changbai Mountains area over the past 240 years by using tree-ring width data. Chinese Journal of Ecology 26(12): 1924-1929. [in Chinese with English abstract].

Zhang, Q.B., G.D. Cheng, T.D. Yao and T.D. Yao. 2003. A 2326year tree-ring record of climate variability on the northeastern Qinghai-Tibetan Plateau. Geophysical Research Letter 30: 1739-1741.

Zhu, H.F., X.Q. Fang, X.M. Shao and Z.Y. Yin. 2009. Tree ringbased February-April temperature reconstruction for Changbai Mountain in Northeast China and its implication for East Asian winter monsoon. Climate of the Past 5: 1-6. 